\title{
Single-Walled Carbon Nanotube Growth with Non-Iron- Group “Catalysts” by Chemical Vapor Deposition
}

\author{
Yoshikazu Homma $(\bowtie)$, Huaping Liu ${ }^{1, \dagger}$, Daisuke Takagi ${ }^{2}$, and Yoshihiro Kobayashi ${ }^{2, *}$ \\ ${ }^{1}$ Department of Physics, Tokyo University of Science, Shinjuku, Tokyo 162-8601, Japan \\ ${ }^{2}$ NTT Basic Research Laboratories, Nippon Telegraph and Telephone Corporation, Atsugi, Kanagawa 243-0198, Japan \\ $\dagger$ Current address: National Institute of Advanced Industrial Science and Technology, Nanotechnology Research Institute, Tsukuba, \\ Ibaraki, 305-8561, Japan \\ ¥ Current address: Department of Applied Physics, Osaka University, Suita, Osaka 565-0871, Japan \\ Received: 2 May 2009 / Revised: 18 August 2009 / Accepted: 19 August 2009 \\ CTsinghua University Press and Springer-Verlag 2009. This article is published with open access at Springerlink.com
}

\begin{abstract}
Various materials have been found to "catalyze" carbon nanotube growth in chemical vapor deposition (CVD) when they become nano-sized particles. These involve not only metals, such as $\mathrm{Pd}, \mathrm{Pt}, \mathrm{Au}, \mathrm{Ag}$, and $\mathrm{Cu}$, but also semiconductors, such as $\mathrm{Si}, \mathrm{Ge}$, and $\mathrm{SiC}$. Alumina and diamond nanoparticles also produce carbon nanotubes. These "catalysts", which are better called "seeds", can be categorized into two types: one type forms a eutectic liquid or highly-mobile alloy with carbon, and carbon atoms precipitate from the eutectic alloy; the other type remains as a solid phase and form a carbon surface layer during CVD growth. In this paper, we review recent studies of SWCNT growth with these non-iron-group materials and highlight the mechanisms involved.
\end{abstract}

\section{KEYWORDS}

Carbon nanotube, catalyst, seed, growth mechanism, chemical vapor deposition, vapor-liquid-solid mechanism

\section{Introduction}

Carbon nanotubes (CNTs) are an interesting material from the viewpoints of not only their excellent properties which promise future applications, but also the mechanism of formation of their peculiar structures [1]. A single-walled CNT (SWCNT) is the most stable form of a single-atomic layer with macroscopic length. An understanding of the formation mechanism is crucial for controlling the SWCNT structure, namely their chirality, which determines their electronic and optical properties
[2]. To date, the most versatile techniques for synthesizing SWCNTs have been those based on catalyst-assisted chemical vapor deposition (CVD) [3]. Common catalyst species are iron-group metals, iron $(\mathrm{Fe})$, cobalt (Co), and nickel (Ni) [4], which are known to have a catalytic function in assisting carbon feedstock cracking and producing graphite layers on a bulk material surface [5]. For these species, a widely-accepted growth model is based on the vapor-liquid-solid (VLS) mechanism as the analog of semiconductor nanowire growth from gold eutectic alloys [6]. During the CVD process, carbon-

Address correspondence to homma@rs.kagu.tus.ac.jp 
bearing molecules are catalytically decomposed on the surface of the catalyst, which is supposed to be in the liquid phase, resulting in the dissolution of carbon atoms into the catalyst particles. Upon supersaturation of carbon concentration in a particle, carbon atoms precipitate from the catalyst, leading to the formation of tubular carbon networks around or on the catalyst. From the viewpoint of carbon solubility and carbide phase formation in the carbonmetal binary phase diagram, $\mathrm{Fe}, \mathrm{Co}$, and Ni should be the elements capable of catalyzing SWCNT growth. However, recently, many other species, palladium $(\mathrm{Pd})$, platinum $(\mathrm{Pt})$, gold $(\mathrm{Au})$, silver $(\mathrm{Ag})$, copper $(\mathrm{Cu})$, and aluminum $(\mathrm{Al})$, have been reported to yield SWCNTs [7-10]. The list is still growing, and is not limited to metals but also encompasses non-metallic species, such as silicon $(\mathrm{Si})$, germanium $(\mathrm{Ge})$, silicon carbide $(\mathrm{SiC})$, and alumina $\left(\mathrm{Al}_{2} \mathrm{O}_{3}\right)$ [11, 12]. Even silica $\left(\mathrm{SiO}_{2}\right)$ has been reported to have the ability to catalyze CNT growth under limited conditions [13, 14]. The VLS picture may still be valid for iron-group metals, but some of the newly found species seem to involve a mechanism out of the frame of VLS. In this paper, we review SWCNT growth with noniron-group materials, and discuss the role of these materials in the CVD process.

\section{Review of experimental results}

Although various kinds of carbon-bearing gas can be used with iron-group metal catalysts, ethanol and acetylene have mainly been used for the newly-found catalyst species $(\mathrm{Pd}, \mathrm{Pt}, \mathrm{Au}, \mathrm{Ag}, \mathrm{Cu}, \mathrm{Ge}, \mathrm{Si}, \mathrm{SiC}$, and $\mathrm{Al}_{2} \mathrm{O}_{3}$, etc.). This is because pyrolysis of ethanol and acetylene takes place easily without assistance from a hot-filament or plasma. Typical growth temperatures are $850-950{ }^{\circ} \mathrm{C}$ for ethanol $[7,11]$. Here, we should note that the term "catalyst" is not appropriate for the non-iron-group materials, and they should actually be called "seeds" for SWCNT growth.

There are two critical conditions for SWCNT growth from the newly-found species: the size of the seed particles and their pretreatment [7]. The particle size for efficient SWCNT growth must be $5 \mathrm{~nm}$ or less, preferably $3 \mathrm{~nm}$ or less. For $\mathrm{Al}_{2} \mathrm{O}_{3}$, larger particles still work, probably because of their microstructures (nano-protrusions) [12]. To increase SWCNT yield, preheating of the particles in air at $850-950{ }^{\circ} \mathrm{C}$ is useful. Seed particles need to be exposed to ethanol vapor immediately after air heating [7]. We think that the air heating process removes hydrocarbon contaminants on the particles and produces a bare surface. Additionally, heating in air has the effect of preventing an increase in size of the metal particles. This might be due to reduced diffusion of the metal atoms in the oxidation atmosphere.

The yields of SWCNT with the newly-found metal species are generally lower than those obtained with the iron-group metals, although Au and Pt give fairly high yields. A comparison of the SWCNT density for Au- and Fe-catalyzed SWCNTs is shown in Fig. 1. The density of SWCNTs with Au is comparable to that with Fe. However, the vertically aligned SWCNT growth that can be induced by Fe or Co [15-17] has never been reported with $\mathrm{Au}$ or Pt. Semiconductor nanoparticles give lower yields than the metal particles. Among $\mathrm{Ge}, \mathrm{Si}$, and $\mathrm{SiC}$, Ge has the highest SWCNT yield. Since the melting point of Ge is much lower than those of $\mathrm{SiC}$ and $\mathrm{Si}$, Ge nanoparticles are likely molten during CVD, which might be related to the higher SWCNT yield [11].
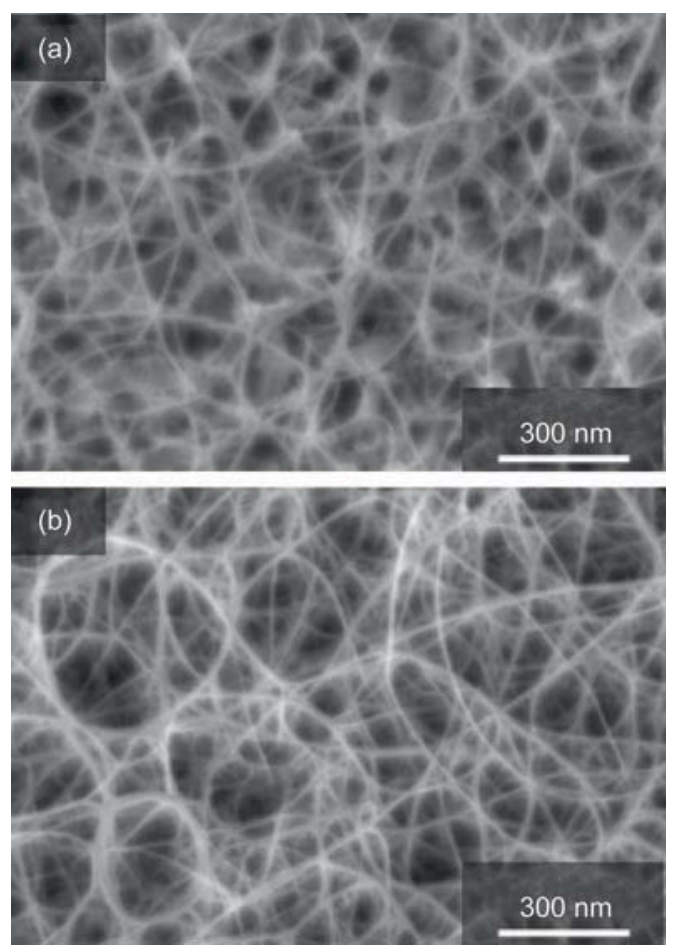

Figure 1 SEM images of SWCNTS grown on an Al hydro-oxide substrate catalyzed by (a) Au and (b) Fe 
Figure 2 shows the morphology difference in SWCNTs grown with $\mathrm{Al}_{2} \mathrm{O}_{3}$ and Fe [18]. The SWCNTs grown with $\mathrm{Al}_{2} \mathrm{O}_{3}$ are short and straight. The average growth rate of SWCNTs with $\mathrm{Al}_{2} \mathrm{O}_{3}$ is about 200 $\mathrm{nm} / \mathrm{min}$, which is much lower than that with Fe (about $1200 \mathrm{~nm} / \mathrm{min}$ ) under the same conditions. Additionally, a low gas pressure $(\sim 2.7 \mathrm{kPa})$ is necessary for the growth of dense SWCNTs with $\mathrm{Al}_{2} \mathrm{O}_{3}$. These results highlight that $\mathrm{Al}_{2} \mathrm{O}_{3}$ particles have different "catalytic" properties from the conventional metal catalysts [18].
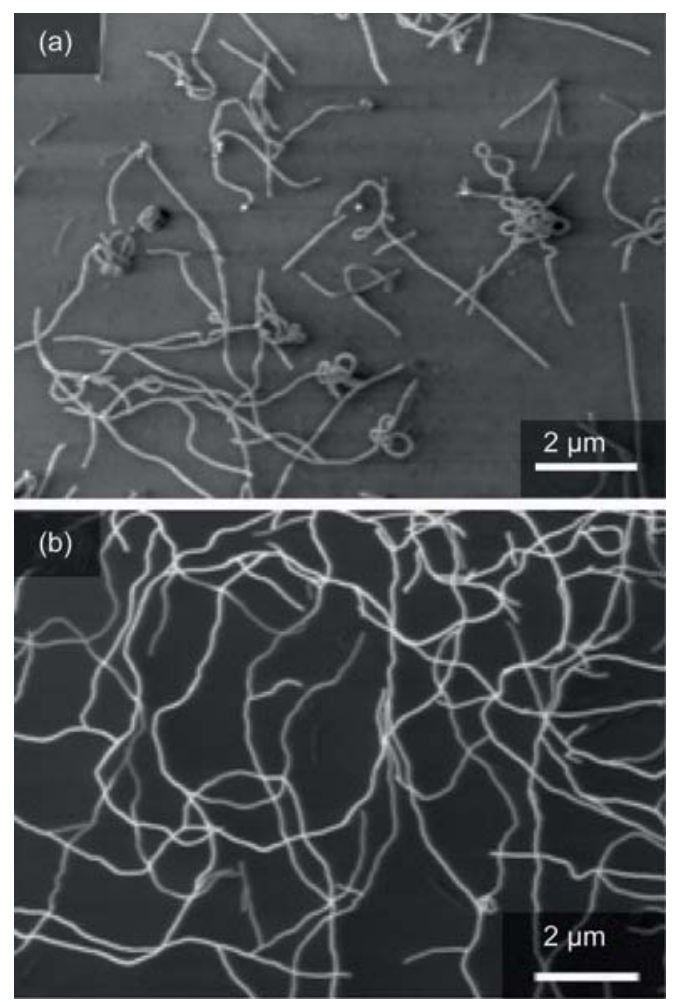

Figure 2 SEM images of SWCNTS grown on a $\mathrm{SiO}_{2}$ substrate catalyzed by (a) $\mathrm{Al}_{2} \mathrm{O}_{3}$ and (b) Fe. The same growth conditions were used. Growth time: 15 min

The reason why a low gas pressure is suitable for nanotube growth with $\mathrm{Al}_{2} \mathrm{O}_{3}$ particles is explained by the low SWCNT growth rate. When the gas pressure is too high, more carbon atoms are provided than those consumed by nanotube growth. This will result in oversupply of carbon, causing carbon accumulation on the particles, and SWCNT growth will be terminated in a short time. Because of the low growth rate of SWCNTs with $\mathrm{Al}_{2} \mathrm{O}_{3}$, a low pressure of carbon source gas can supply carbon atoms at an appropriate rate for growth of the SWCNTs.

\section{CNT growth using metal nanoparticles}

$\mathrm{Pd}$ and Pt, like the typical metals able to catalyze CNT growth ( $\mathrm{Fe}, \mathrm{Co}$, and $\mathrm{Ni})$, have eutectic alloy phase diagrams with carbon. Thus, the VLS mechanism is able to explain CNT precipitation from nanosized $\mathrm{Pd}$ and $\mathrm{Pt}$. On the other hand, $\mathrm{Au}, \mathrm{Ag}$, and $\mathrm{Cu}$ have low solubilities of carbon [19-21]. Nevertheless, these elements also produce SWCNTs. In addition, $\mathrm{Au}$ particles around $10 \mathrm{~nm}$ produce amorphous carbon wires as shown in Fig. 3 [22]. The carbon nanowires have a gold "cap" on the top of the wire. This shape is similar to a semiconductor nanowire with a gold "cap", which is believed to result from VLS growth [23]. This suggests that the gold nanoparticles have sizable carbon solubility. Actually, gold has a eutectic alloy phase diagram with carbon, and the carbon concentration in bulk $\mathrm{Au}$ at the eutectic point is $\sim 4.7 \%$ [19]. Even for such a low content of carbon, the VLS model could be applied to the $\mathrm{C}-\mathrm{Au}$ binary system.

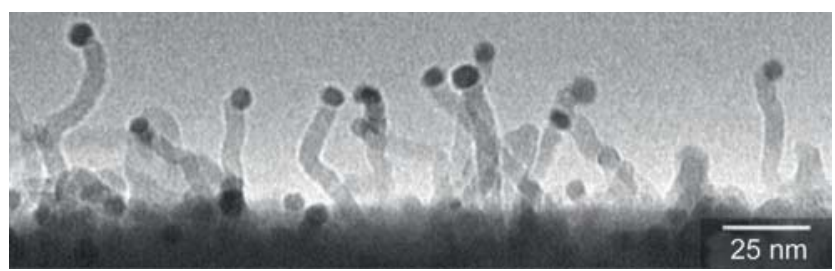

Figure 3 TEM image of an amorphous carbon nanowire grown using Au particles

The carbon solubility becomes higher in nanoparticles: this is explained by the size effect on the binary alloy phase diagram [24]. Here, we take the $\mathrm{Au}-\mathrm{C}$ system as an example. When the particle size decreases, the melting points of both $\mathrm{Au}$ and $\mathrm{C}$ decrease [25]. The melting point reduction causes the shift of the phase boundary between liquid ( $\mathrm{Au}$ $+\mathrm{C}$ ) and liquid $(\mathrm{Au})+$ solid $(\mathrm{C})$ to higher carbon concentrations as schematically shown in Fig. 4 [24]. Thus, the carbon solubility in the $\mathrm{Au}+\mathrm{C}$ droplet, or the carbon concentration at the phase boundary at the CVD temperature, increases with decreasing $\mathrm{Au}$ particle size. The increase of carbon solubility with decreasing Au particle size explains the transition from carbon nanowire to nanotube formation in small $\mathrm{Au}$ particles [22]. Since the driving force of carbon precipitation from the $\mathrm{Au}+\mathrm{C}$ droplet is proportional to the concentration difference between 


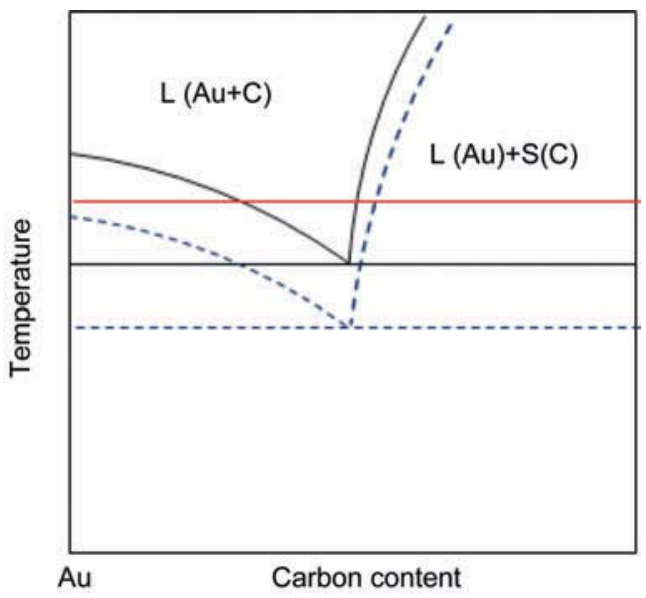

Figure 4 Schematic illustration of the $\mathrm{Au}-\mathrm{C}$ phase diagram. Broken lines are for smaller particles. The red line denotes the CVD temperature

the supersaturated carbon in the droplet and the equilibrium value at the phase boundary, amorphous carbon wire growth is suppressed for smaller $\mathrm{Au}$ particles. The increase in the carbon concentration in the particle also raises the carbon concentration on the Au particle surface and drives formation of graphene-like carbon networks, i.e., an SWCNT cap.

Thus, even for the metals with low carbon solubility, the VLS mechanism is a plausible explanation of CNT formation. However, it should be noted that a liquid phase is not essential for the VLS mechanism. Recent in situ transmission electron microscopy (TEM) observations have revealed that multi-walled CNTs grow continuously from crystalline $\mathrm{Fe}_{3} \mathrm{C}$ particles at $600{ }^{\circ} \mathrm{C}$ [26]. Although the $\mathrm{Fe}_{3} \mathrm{C}$ particle shows clear lattice fringes, the crystal structure occasionally fluctuates during CVD, indicating that the particles are near their melting point. A similar result has been reported for Ge nanowire growth with a Au catalyst [27]. At just below the melting point, the solid particle might have a high density of vacancies, which allows efficient diffusion of carbon atoms. The essential feature of the VLS mechanism is carbon precipitation from the metal-carbon (bulk) alloy, not necessarily from a droplet.

\section{CNT growth using semiconductor and alumina nanoparticles}

Among the non-metallic "catalysts" employed in SWNT growth, Ge, Si, SiC, and alumina, only Ge can be assumed to involve VLS, because the melting point of bulk Ge is relatively low, $952{ }^{\circ} \mathrm{C}$. In contrast, $\mathrm{Si}, \mathrm{SiC}$, and alumina are thought to remain solid during ethanol CVD. Their bulk melting points are high, $1410{ }^{\circ} \mathrm{C}$ for $\mathrm{Si}$ and higher than $2000{ }^{\circ} \mathrm{C}$ for $\mathrm{SiC}$ and alumina. A mechanism other than VLS must be involved for these solid "catalysts".

Very recently, diamond nanoparticles were found to act as seeds for CNT growth [28]. Interestingly, the diamond nanoparticles did not fuse with each other even when agglomerated particles were used for CVD, as shown in Fig. 5. This result strongly suggests that CNTs were formed from solid carbon nanoparticles. Furthermore, since bulk diffusion of carbon atoms through the diamond particle is unlikely, the diamond surface must play an important role in SWCNT formation.

Si nanoparticles likely react with carbon during CVD and form SiC on the surface. Thus, Si can be regarded as the same as $\mathrm{SiC}$ in terms of $\mathrm{CNT}$ formation ability. Alumina seems very different from $\mathrm{Si}$ and $\mathrm{SiC}$. However, it was found that carbon deposition or graphitic carbon formation occurred on

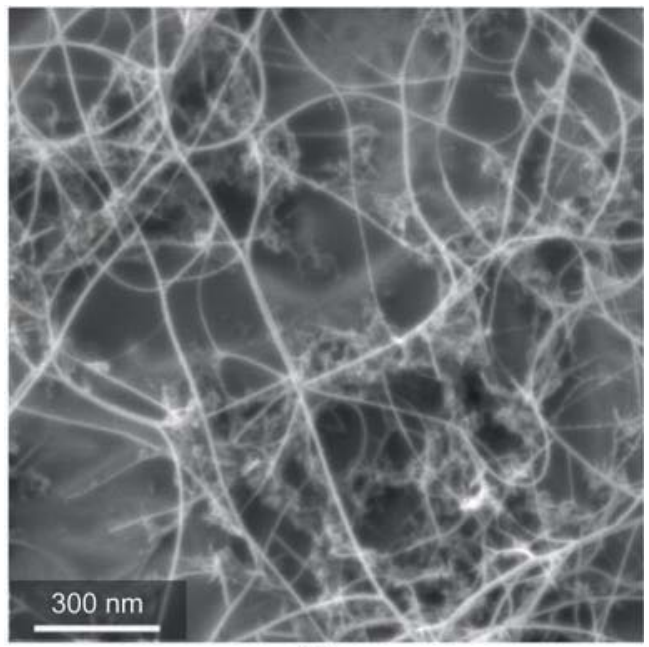

(a)

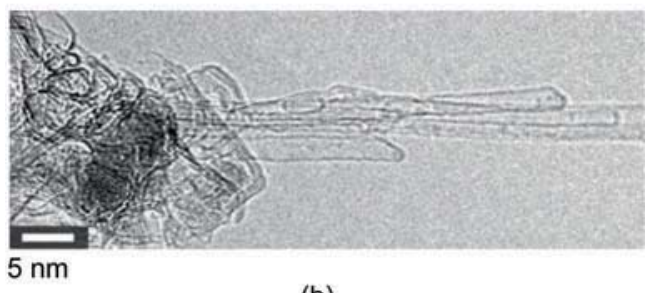

(b)

Figure 5 SEM image (a) and TEM image (b) of SWCNTs grown from diamond nanoparticles 
a sapphire substrate, while thick carbon deposition barely occurred on a $\mathrm{SiO}_{2}$ surface [29]. Since the chemical composition of sapphire is the same as alumina, alumina nanoparticles are likely coated with a thin carbon layer during CVD.

Therefore, for diamond, $\mathrm{Si}, \mathrm{SiC}$, and alumina it seems clear that it is carbon or carbon-coated nanoparticles which serve as seeds of SWCNT growth (Fig. 6). Several studies have shown that SWCNTs can be grown on $\mathrm{SiO}_{2}$ substrates without metal catalysts $[13,14]$. In our experiments, by pretreatment of $\mathrm{SiO}_{2}$ at $950{ }^{\circ} \mathrm{C}$ or a higher temperature in $\mathrm{H}_{2}$ before CVD, a high density of SWCNTs could be grown. We also found that nano-scale carbon particles were produced besides SWCNTs [30]. Based on these results, we propose that the annealing of $\mathrm{SiO}_{2}$ substrates in $\mathrm{H}_{2}$ at high temperature generates defects on their surfaces, and these defects provide nucleation sites for carbon nanoparticles.

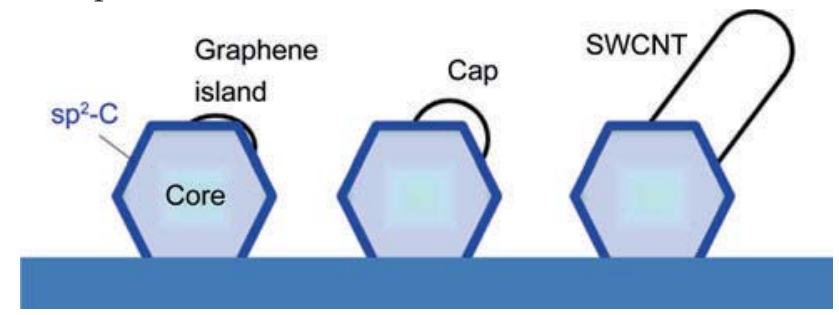

Figure 6 Schematic illustration of growth of SWCNT on an sp²solid-carbon surface. The core can be diamond, Si, SiC, or alumina

\section{CNT growth mechanism from solid carbon particles}

All of those results suggest that there is a path for CNT formation on the solid carbon surface other than the VLS mechanism, i.e., carbon precipitation from a carbon alloy. Takagi et al. proposed the formation of a graphene island having a five-membered ring on the $\mathrm{sp}^{2}$-relaxed solid diamond surface [28]. In an early growth stage of a small domain of a graphene sheet on a Ni surface, a graphene island including a fivemembered ring was shown to be energetically more favorable than a graphene sheet composed of all sixmembered rings [31]. A similar $\mathrm{sp}^{2}$-bonded island with five-membered rings (a "cap") was shown to be formed following the diffusion of $\mathrm{C}$ atoms on a 1-nm Fe particle surface by $a b$ initio molecular dynamics simulations [32]. Such graphene island formation is generally supposed to occur on an $\mathrm{sp}^{2}$-solid carbon surface. When a graphene island with five-membered rings is partially formed on a nanoparticle, it lifts off the particle surface except for the edge of the island and it becomes an SWCNT-cap, as shown in Fig. 6. The edge of the SWCNT-cap is chemically active and acts as the incorporation site for carbon adatoms. This promotes SWCNT growth. However, it is not clear what kind of interaction is present between the carbon atoms at the edge of the cap and the seed particle. The interaction should not be so strong as to prevent incorporation of carbon atoms, but not too weak as to maintain an open end of the SWCNT [33]. Theoretical studies of the nature of the carbon-seed interaction are desirable.

The basic idea of this curved graphene island nucleation is that graphene patches are self-formed without catalysis by a metal. Evidence is shown in Fig. 7(a). This is a TEM image of a flat $\mathrm{SiO}_{2}$ surface, where a graphene sheet is formed on the surface after acetylene CVD. The size of the sheet needs not be large and such a small graphene patch is easily formed. On the Fe catalyst surface, a curved sheet is formed, showing that the curved surface causes CNT cap formation. The cap in Fig. 7(b) was created by the Fe catalyst, but a graphene patch can also be selfcreated without a catalyst as shown in Fig. 7(a). A nano-scale curved surface thus provides a template
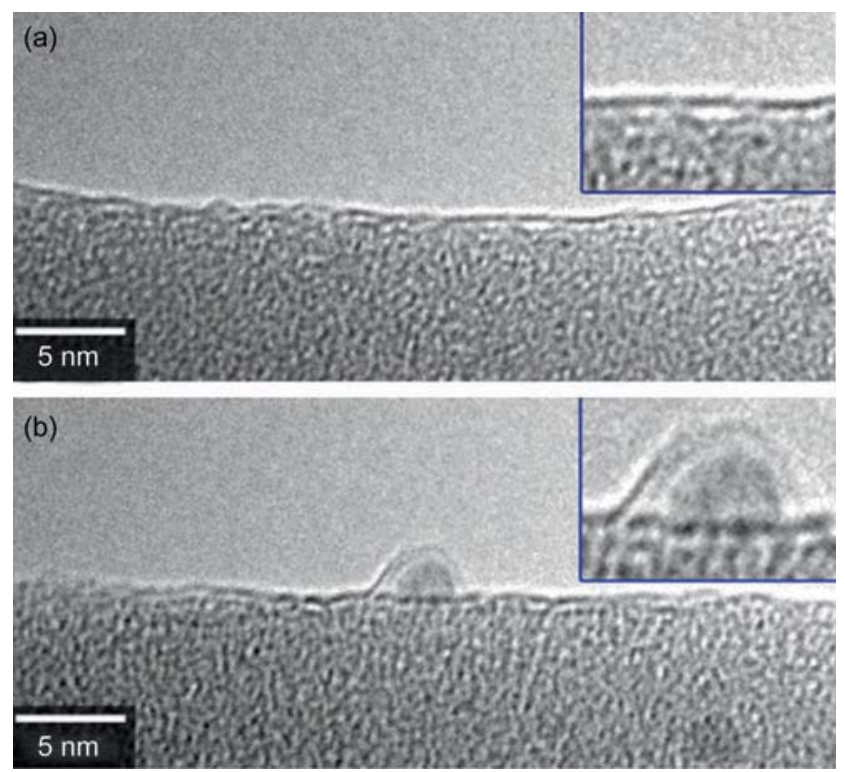

Figure 7 TEM images of (a) a graphene sheet on a $\mathrm{SiO}_{2}$ surface and (b) a curved cap structure on a Fe nanoparticle 
for CNT-cap formation [11]. In some case, the cap covers all the surface of the nanoparticle, resulting in failure of CNT growth. In some case, the cap is smaller than the nanoparticle and lifts off the surface, resulting in successful CNT formation.

\section{Conclusions}

The various catalysts for SWCNT formation found so far can be categorized into two groups. For metals, even those with low carbon solubility, the VLS mechanism (i.e., carbon precipitation from a eutectic alloy, not necessarily in the liquid phase) is the most plausible mechanism of CNT formation. Ge is also included in this group. The ability of diamond, $\mathrm{Si}, \mathrm{SiC}$, and alumina to act as solid "catalysts" can be explained in terms of becoming carbon-coated nanoparticles. On these carbon-saturated surfaces, a graphene island with five-membered rings is formed as the nucleus of an SWCNT. A nano-scale curved surface thus provides a template for CNT-cap formation.

\section{Acknowledgements}

The authors would like to thank Hideto Yoshika, Osaka University, for supporting TEM observations. They acknowledge the support for their research in this field from CREST, Japan Science and Technology Agency, and a Grant-in-Aid for Scientific Research on Priority Areas (No. 19054015) from the Ministry of Education, Culture, Sports, Science, and Technology (MEXT), Japan.

\section{References}

[1] Dresselhaus, M. S.; Dresselhaus, G.; Avouris, P. Carbon Nanotubes Synthesis, Structure, Properties, and Applications; Springer: Berlin, 2001.

[2] Saito, R.; Dresselhaus, G.; Dresselhaus, M. S. Physical Properties of Carbon Nanotubes; Imperial College Press: London, 1999.

[3] Loiseau, A.; Blasé, J. -C.; Charlier, P.; Gadelle, P.; Journet, C.; Laurent, C.; Peigney, A. Synthesis Methods and Growth Mechanisms. In Understanding Carbon Nanotubes: From Basics to Applications; Loiseau, A.,
Launois, P., Petit, P., Roche, S., Salvetat, J. -P., Eds.; Springer: Berlin, 2006; pp. 49-130.

[4] Kong, J.; Cassell, A. M.; Dai, H. Chemical vapor deposition of methane for single-walled carbon nanotubes. Chem. Phys. Lett. 1998, 292, 567-574.

[5] Hamilton, J. C.; Blakely, J. M. Carbon segregation to single crystal surfaces of Pt, Pd and Co. Surf. Sci. 1980, 91, 199-217.

[6] Gavillet, J.; Loiseau, A.; Journet, C.; Willaime, F.; Ducastelle, F.; Charlier, J. C. Root-growth mechanism for single-wall carbon nanotubes. Phys. Rev. Lett. 2001, 87, 275504.

[7] Takagi, D.; Homma, Y.; Hibino, H.; Suzuki, S.; Kobayashi, Y. Single-walled carbon nanotube growth from highly activated metal nanoparticles. Nano Lett. 2006, 6, 2642 -2645 .

[8] Zhou, W.; Han, Z.; Wang, J.; Zhang, Y.; Jin, Z.; Sun, X.; Zhang, Y.; Yan, C.; Li, Y. Copper catalyzing growth of single-walled carbon nanotubes on substrates. Nano Lett. 2006, 6, 2987-2990.

[9] Bhaviripudi, S.; Mile, E.; Steiner, S. A.; Zare, A. T.; Dresselhaus, M. S.; Belcher, A. M.; Kong, J. CVD synthesis of single-walled carbon nanotubes from gold nanoparticle catalysts. J. Am. Chem. Soc. 2007, 129, 1516-1517.

[10] Yuan, D.; Ding, L.; Chu, H.; Feng, Y.; McNicholas, T. P.; Liu, J. Horizontally aligned single-walled carbon nanotube on quartz from a large variety of metal catalysts. Nano Lett. 2008, 8, 2576-2579.

[11] Takagi, D.; Hibino, H.; Suzuki, S.; Kobayashi, Y.; Homma, Y. Carbon nanotube growth from semiconductor nanoparticles. Nano Lett. 2007, 7, 2272-2275.

[12] Liu, H.; Takagi, D.; Ohno, H.; Chiashi, S.; Chokan, T.; Homma, Y. Growth of single-walled carbon nanotubes from ceramic particles by alcohol chemical vapor deposition. Appl. Phys. Express 2008, 1, 014001.

[13] Liu, B.; Ren, W.; Gao, L.; Li, S.; Pei, S.; Liu, C.; Jiang, C.; Cheng, H. -M. Metal-catalyst-free growth of singlewalled carbon nanotubes. J. Am. Chem. Soc. 2009, 131, 2082-2083.

[14] Huang, S.; Cai, Q.; Chen, J.; Qian, Y.; Zhang, L. Metalcatalyst-free growth of single-walled carbon nanotubes on substrates. J. Am. Chem. Soc. 2009, 131, 20942095.

[15] Murakamia, Y.; Chiashi, S.; Miyauchi Y.; Hu, M.; Ogura, M.; Okubo, T.; Maruyama, S. Growth of vertically aligned 
single-walled carbon nanotube films on quartz substrates and their optical anisotropy. Chem. Phys. Lett. 2004, 385, 298-303.

[16] Noda, S.; Hasegawa, K.; Sugime, H.; Kakehi, K.; Zhang Z.; Maruyama, S.; Yamaguchi, Y. Millimeter-thick singlewalled carbon nanotube forests: Hidden role of catalyst support. Jpn. J. Appl. Phys. 2007, 46, L399-L401.

[17] Ohno, H.; Takagi, D.; Yamada, K.; Chiashi, S.; Tokura, A.; Homma, Y. Growth of vertically aligned single-walled carbon nanotubes on alumina and sapphire substrates. Jpn. J. Appl. Phys. 2008, 47, 1956-1960.

[18] Liu, H.; Takagi, D.; Chiashi, S.; Chokan, T.; Homma, Y. Investigation of catalytic properties of $\mathrm{Al}_{2} \mathrm{O}_{3}$ particles in the growth of single-walled carbon nanotubes. J. Nanosci. Nanotechnol., in press.

[19] Okamoto, H.; Massalski, T. B. The Au-C (gold-carbon) system. Bull. Alloy Phase Diag. 1984, 5, 378-379.

[20] Hansen, M.; Anderko, K. Constitution of Binary Alloys; McGraw-Hill: New York, 1958.

[21] Oden, L. L.; Gokcen, N. A. Cu-C and Al-Cu-C phase diagrams and thermodynamic properties of $C$ in the alloys from $1550{ }^{\circ} \mathrm{C}$ to $2300^{\circ} \mathrm{C}$. Metall. Mat. Trans. B, 1992, 23, 453-458.

[22] Takagi, D.; Kobayashi, Y.; Hibino, H.; Suzuki, S.; Homma, Y. Mechanism of gold-catalyzed carbon material growth. Nano Lett. 2008, 8, 832-835.

[23] Wagner, R. S.; Ellis, W. C. Vapor-liquid-solid mechanism of single crystal growth. Appl. Phys. Lett. 1964, 4, 8990.

[24] Tanaka, T.; Hara, S. Thermodynamic evaluation of nanoparticle binary alloy phase diagrams. Z. Metallkd. 2001, 92, 1236-1241.

[25] Wautelet, M. Estimation of the variation of the melting temperature with the size of small particles on the basis of a surface-phonon instability model. J. Phys. D. Appl. Phys. 1991, 24, 343-346.

[26] Yoshida, H.; Takeda, S.; Uchiyama, T.; Kohno, H.; Homma, Y. Atomic-scale in situ observation of carbon nanotube growth from solid state iron carbide nanoparticles. Nano Lett. 2008, 8, 2082-2086.

[27] Kodambaka, S.; Tersoff, J.; Reuter, M. C.; Ross, F. M. Germanium nanowire growth below the eutectic temperature. Science 2007, 316, 729-732.

[28] Takagi, D.; Kobayashi, Y.; Homma Y, Carbon nanotube growth from diamond. J. Am. Chem. Soc. 2009, 131, 6922-6923.

[29] Liu, H.; Takagi, D.; Chiashi, S.; Homma ,Y. Controlled growth of horizontally aligned single-walled carbon nanotube arrays by gas flow process. Nanotechnology 2009, 20, 345604.

[30] Liu, H.; Takagi, D.; Chiashi, S.; Homma, Y. The growth of single-walled carbon nanotubes on a silica substrate without using a metal catalyst. Carbon, in press.

[31] Fan, X.; Buczko, R.; Puretzky, A. A.; Geohegan, D. B.; Howe, J. Y.; Pantelides, S. T.; Pennycook, S. J. Nucleation of single-walled carbon nanotubes. Phy. Rev. Lett. 2003, 90, 145501.

[32] Raty, J. Y.; Gygi, F.; Galli, G. Growth of carbon nanotubes on metal nanoparticles: A microscopic mechanism from ab initio molecular dynamics simulations. Phy. Rev. Lett. 2005, 95, 096103.

[33] Ding, F.; Larsson, P.; Larsson, J. A.; Ahuja, R.; Duan, H.; Rosén, A.; Bolton, K. The importance of strong carbonmetal adhesion for catalytic nucleation of single-walled carbon nanotubes. Nano Lett. 2008, 8, 463-468. 